\title{
'Measuring' Physical Literacy and Related Constructs: A Systematic Review of Empirical Findings
}

\author{
Lowri C. Edwards ${ }^{1} \cdot$ Anna S. Bryant $^{1} \cdot$ Richard J. Keegan $^{2} \cdot$ Kevin Morgan $^{1}$ • \\ Stephen-Mark Cooper ${ }^{1} \cdot$ Anwen M. Jones $^{1}$
}

Published online: 15 November 2017

(C) The Author(s) 2017. This article is an open access publication

\begin{abstract}
Background The concept of physical literacy has received increased research and international attention recently. Where intervention programs and empirical research are gaining momentum, their operationalizations differ significantly.

Objective The objective of this study was to inform practice in the measure/assessment of physical literacy via a systematic review of research that has assessed physical literacy (up to 14 June, 2017).

Methods Five databases were searched using the Preferred Reporting Items for Systematic Reviews and Meta-Analyses for Protocols guidelines, with 32 published articles meeting the inclusion criteria. English-language, peer-reviewed published papers containing empirical studies of physical literacy were analyzed using inductive thematic analysis.
\end{abstract}

Electronic supplementary material The online version of this article (https://doi.org/10.1007/s40279-017-0817-9) contains supplementary material, which is available to authorized users.

Anna S. Bryant

anbryant@cardiffmet.ac.uk

1 Cardiff School of Sport and Health Sciences, Cardiff Metropolitan University, Cyncoed Road, Cardiff, CF23 6XD, UK

2 Faculty of Health, Research Institute for Sport and Exercise, University of Canberra, Canberra, ACT, Australia
Results Qualitative methods included: (1) interviews; (2) open-ended questionnaires; (3) reflective diaries; (4) focus groups; (5) participant observations; and (6) visual methods. Quantitative methods included: (1) monitoring devices (e.g., accelerometers); (2) observations (e.g., of physical activity or motor proficiency); (3) psychometrics (e.g., enjoyment, self-perceptions); (4) performance measures (e.g., exergaming, objective times/distances); (5) anthropometric measurements; and (6) one compound measure. Of the measures that made an explicit distinction: $22(61 \%)$ examined the physical domain, eight (22\%) the affective domain; five (14\%) the cognitive domain; and one (3\%) combined three domains (physical, affective, and cognitive) of physical literacy. Researchers tended to declare their philosophical standpoint significantly more in qualitative research compared with quantitative research.

Conclusions Current research adopts diverse often incompatible methodologies in measuring/assessing physical literacy. Our analysis revealed that by adopting simplistic and linear methods, physical literacy cannot be measured/assessed in a traditional/conventional sense. Therefore, we recommend that researchers are more creative in developing integrated philosophically aligned approaches to measuring/assessing physical literacy. Future research should consider the most recent developments in the field of physical literacy for policy formation. 


\section{Key Points}

This article is the first to provide a systematic review of the measure/assessment attempts of the concept of physical literacy and its related constructs (i.e., physical activity and health outcomes) and is the first to suggest that by adopting simplistic and linear methods, physical literacy cannot be measured/ assessed in the traditional/conventional sense.

Recommendations for future research include a need for more empirical research on the concept of physical literacy; essentially, there is a need for more research that is open about the definition and philosophical approach used and theories tested.

Future research should measure/assess beyond the constructs of physical proficiencies, and aim to measure/assess physical literacy from a more holistic perspective.

\section{Introduction}

\subsection{Background to the Concept of Physical Literacy}

In recent years, the concept of physical literacy has gained increasing international political attention and has been integrated into several educational and sport policies $[1,2]$. It is proposed that physical literacy influences important health outcomes, such as cardiovascular fitness, strength, motor skills, and obesity status [3], and it is associated with a wide array of behavioral, psychological, social, and physical variables [4]. Consequently, some scholars and educational administrations have proposed that physical literacy is as important to a child's development as literacy and numeracy [5-7]. While many policy makers and stakeholders currently advocate physical literacy programs and interventions, the definitions of physical literacy adopted by these schemes differ [1, 4], thus causing disparities of how to best operationalize and measure/assess the concept.

A recent systematic review outlined the challenges of many definitions of physical literacy and related constructs currently under debate such as different misinterpretations and lack of consistency with operationalization [4]. Some of these definitions focused solely on the physical and motor competence aspects of physical literacy, including: running speed [8]; motor development [9]; fundamental movement skills (FMS) [10]; and the use of 'exergaming' technology as a tool to develop physical competence $[11,12]$. Other countries define physical literacy as applying FMS with confidence (Northern Ireland) [5] in a range of multiple environments to benefit the development of the whole person (Physical and Health Education Canada) [13]. A number of related constructs to physical literacy have been previously identified such as physical activity [4]. Importantly, the related constructs describe concepts that were related to, but not synonymous with, physical literacy.

In an effort to summarize and synthesize this literature, Edwards et al. [4] conducted a systematic review of definitions and associations of physical literacy. They found that the majority of papers (70\%) adopted a 'Whiteheadian' definition of physical literacy and that adopted by the International Physical Literacy Association namely as: "the motivation, confidence, physical competence, knowledge and understanding to value and take responsibility for engagement in physical activities for life" [14]. Specifically, Whitehead's [14] concept of physical literacy is based on the premise of a holistic individualized journey, with three identified philosophical underpinnings of phenomenology, existentialism, and monism-this differs from many of the competing definitions outlined above, which often do not detail their philosophical underpinnings (see [4, 5, 13, 15]). Recent developments in the field, specifically the work of Dudley et al. [16], acknowledged that while philosophical approaches may differ between public health, sport, and educational policies, there is cohesion within policy about the purpose of physical literacy. Overall, there are inconsistencies in the interpretation and operationalization of physical literacy that have led to a lack of clarity in intervention design [4]. Indeed, these insights emphasize the need for a critical discussion of philosophical paradigms to ensure the conceptualization, measurement, and interventions deployed in different policies are carefully aligned with a specific philosophical approach.

Debates acknowledging these philosophical standpoints have questioned whether physical literacy can be measured/assessed in any conventional sense, or at least what might constitute an appropriate method of collecting empirical data for the study of physical literacy [17], which also aligns a definition and the proposed philosophy [4]. There is also the important point that the three above philosophical standpoints are not intended to be combined, but rather three stand-alone self-contained perspectives on ontology (what is the nature of that reality?) and epistemology (how can we come to know and understand this reality) $[18,19]$.

In this context, it is important to acknowledge what is meant by measurement/assessment. According to Huitt et al. [20], measurement is the process of quantifying 
objects/events, and assessment is the process of gathering measurement data to better understand an issue. In qualitative research "measurement is the process observing and recording the observations that are collected as part of a research effort" [21]. For the purpose of this article, the term measuring/assessing was taken to include charting, monitoring, evaluating, characterizing, and/or observing physical literacy, within empirical research studies. Empirical research is one method of gaining a greater understanding of the concept of physical literacy and examining it helps to identify how a concept can be operationalized: i.e., translated from an abstract theoretical concept into a tractable measurable entity. Empirical research is the accumulation of evidence for or against any particular theory, and involves planned experimental or non-experimental designs [22], wherein 'non-experimental' can also include qualitative designs. In the present review, empirical data included formal experimentation and non-experimental designs, which included interviews, open-ended questionnaires, reflective diaries, focus groups, participant observations, and visual methods to explore the concept of physical literacy. Experimental empirical studies included a treatment, or intervention, with hypotheses, whereas non-experimental empirical studies include exploratory and observational research such as case studies, surveys, field research, and correlation research [23].

\subsection{Grasping the Nettle: Philosophical Assumptions}

As noted by Dennett [24]: "There is no such thing as philosophy-free science; there is only science whose philosophical baggage is taken on board without examination". As such, assumptions about the philosophy of science permeate all science, but are particularly pronounced in the study of physical literacy, as it is proposed from the outset as a concept steeped in philosophical language such as monism, existentialism, and phenomenology [15, 25]. Some philosophers and methodologists insist that it is vital to both declare one's position prior to engagement with a question/problem, as well as ensuring alignment between ontology, epistemology, and methodology $[18,19]$. In this scenario, answers to the questions posed above come as coherent, 'aligned' sets, such that decisions regarding ontology determine the most suitable epistemology, and those determine the most appropriate methodology. Others have observed that scientific endeavors can move along without any such efforts, indeed terming this 'normal' science [26, 27]. Hassmén et al. [28] have recently made the clear case that failures to acknowledge and address philosophical assumptions are at the heart of a number of tensions and crises within sport and exercise research.

Of course, the decision regarding whether this area of research is 'in crisis' is entirely subjective, but in proposing the very concept of physical literacy, Whitehead [15, 25] had ostensibly decided that the confluence of research between physical education (PE), physical activity, health, and motor learning was experiencing a crisis, for example, from inconsistent findings, poor or inconsistent implementation, or falling popular interest/understanding. Furthermore, Whitehead was arguing, both implicitly and explicitly, that a significant portion of this 'crisis' was being generated by either inappropriate or missing philosophical assumptions, for example, the seemingly straightforward mechanical assumption that more physical activity in childhood (in both volume and intensity) leads to improved motor skills, which automatically leads to lifelong physical activity, and improved health outcomes. Such an approach would stem from an 'assumption-set' termed positivism, which asserts that observations made by scientists can and should be completely unbiased and neutral, and that -if sufficient unbiased observations are made - then the underlying mechanisms and explanations will 'emerge' and become obvious, leading to theoretical understanding. That understanding can be used to generate specific refined hypotheses, which are then tested in further observations. Implicitly or explicitly, this is the core assumption underlying many scientific studies, even though many of its core assumptions have been disproved [29-31]. It is acknowledged that there are very many different versions of positivism, and indeed post-positivism, but at the broad level the core assumptions remain very similar.

Nevertheless, it is important to ask whether these assumptions are applicable to the concept of physical literacy. Like positivism, several 'sets' of assumptions have been proposed arguing that the reality of physical literacy is not the same everywhere, for everyone, and thus cannot be measured in an unbiased, neutral, or consistent way. Broadly classified under the banner of 'interpretivism', these approaches rule out both the prospect of objective measurement, and the 'reduction' of a complex phenomenon to its component parts for ease of measurement [32]. Fundamentally, this argument is that the focus of physical literacy should be the personal experience: a highly subjective integration of many different experiences spanning physical, emotional, mental, and social phenomena, i.e., the only place all those influences truly 'integrate' into a single experience is the individual's consciousness $[15,25]$. In this interpretation, it is unlikely that objective measurement would work, and all we could legitimately attempt would be to track, characterize, and seek to understand each individual's experience. Notably, all the authors and researchers within these paradigms are emphatic that such an approach is extremely appropriate legitimate science: more legitimate in fact than applying positivist assumptions to such phenomena (see also 
Gergen's constructionist work in PE [33-35]). As a final point, other assumption sets exist, including: critical rationalism [30, 31]; critical realism [36, 37]; pan-critical rationalism [38, 39]; and more, but these have not yet been applied in the study of physical literacy.

As a broad summary, two approaches have emerged in relation to how one understands the concept of physical literacy [17]. These approaches are characterized as idealist and pragmatic perspectives, and have previously been referred to as 'academic' and 'practical' approaches [40]. An idealist perspective argues that physical literacy is a holistic concept, and therefore the three commonly cited domains of physical literacy (physical, affective, and cognitive) cannot be separated [2]. As such, measuring those domains of physical literacy separately would contradict the holistic philosophical underpinnings of the concept. Consequently, idealists are more likely to explore the concept of physical literacy through qualitative research approaches, such as in-depth interviews, reflections, and observations.

Other scholars have adopted a more pragmatic perspective when seeking to measure the concept of physical literacy [41, 42]. A practical perspective seeks to generate measures that are compatible with evidence-based practice, and contends that research is appraised on its practical implications [43-45]. Pragmatists argue that evidence and practical approaches to the concept of physical literacy are required to change current practices [46]. As a result, pragmatists may choose any methodologies that are compatible with these aims, and are therefore open to using a range of research methods including both qualitative and quantitative [46]. This could be seen as combining the strengths of various methods, yet without critical oversight, it could also be combining the limitations of different approaches. To further complicate this debate, it appears that some researchers adopt a 'holistic' definition, yet appreciate the need for an operational (practical) method of measuring physical literacy [4]. Compounding the tensions caused by these conflicting perspectives, there has been an increasing demand for measures/assessments of physical literacy over at least 7 years [47].

A range of initiatives and programs have emerged from the pragmatic approach towards operationalizing physical literacy [1]. Kiwi Sport is an initiative adopted in New Zealand, whereby an emphasis is placed upon non-standardized games, which are used to assess fundamental motor skills [48]. Alternatively, the Scottish 'Basic Moves' program evaluates fundamental motor skills through a Test of Gross Motor Development [48]. A criticism of these approaches is that they mainly focus on physical and motor capability, over and above other psychological components of physical literacy. Work in Wales has attempted to measure/assess the physical competence element of physical literacy through a validated 'Dragon Challenge' obstacle course [49]. In Canada, an attempt has been made to devise and validate an alternative assessment to capture all elements of physical literacy via the Canadian Assessment for Physical Literacy [41, 42]. This approach attempted to identify the current and most favored measurement approaches for each recognized component of physical literacy, competence, confidence, motivation, and knowledge, but has been criticized for treating them as quite separate, and still providing a disproportional focus on physical and motor competence. Some national 'Report Cards on Physical Activity in Children and Youth' have acknowledged physical literacy as an indicator, however, some countries have expressed that data on physical literacy are 'insufficient' to provide an overall grade [50, 51].

Further, the importance of physical literacy has been acknowledged by the United Nations Educational, Scientific and Cultural Organisation to generate healthy, able, and active citizens as an outcome of high-quality PE [52]. While it is encouraging that the physical literacy agenda is advancing on a practical level, the degree to which these measurement/assessment attempts capture the multifaceted and relatively unique characteristics of physical literacy remains questionable [53]. The current physical literacy initiatives have centered on children and youth populations, with very little focus on pre-adolescent and adult populations. Further, alignment between definition, philosophy, and measures of physical literacy are yet to be explored [4].

Overall, the tension appears to be between the desire to develop consistent, reliable, and valid measures of physical literacy, vs. the viewpoint that physical literacy is inherently complex and dynamic and thus not readily measured using such instruments. We do not currently know what measures/assessments are most appropriate for different age groups and environments. To help resolve this tension at the heart of physical literacy research, a systematic review of current empirical research-including methods of measuring/assessing the concept of physical literacywas conducted to facilitate new insight and clarify key considerations. Previous narrative reviews on physical literacy outlined the importance of assessing participants' knowledge within the concept of physical literacy [54], and emphasized the current lack of robust empirical tools to assess physical literacy $[48,55]$. It is important to note, however, that these reviews have not focused solely on measurement attempts, nor were they conducted using a transparent systematic process. Recent attention has emphasized the benefits of systematic reviews, which provide rigorous and transparent methods as a means of minimizing bias and offering a complete coherent overview of contemporary knowledge on a topic [56, 57]. While rigorous and transparent, the analytic steps and presentation of findings in systematic reviews can vary, to 
address "research questions in different ways with each method" [58].

Two systematic reviews concerning physical literacy and its related constructs have been conducted; specifically, one that investigated the effectiveness of school-based physical activity interventions on students' health-related fitness knowledge [59] and another that examined the definitions, underlying philosophy, and hypothesized associations/correlates of physical literacy [4]. The findings of the latter suggest a need to operationalize physical literacy as clearly as possible to generate contextualized interpretable (i.e., meaningful) findings. Identifying the similarities and differences in approaches to conceptualizing (and subsequently measuring/assessing) physical literacy will facilitate a degree of pluralism wherein different ideas can compete and be evaluated over time [4]. Accordingly, this development of different well-articulated frameworks for studying physical literacy, if achieved, will allow scholars to decipher which interpretation of physical literacy is being tested, supported, or refuted [4]. In turn, practitioners and policy makers can evaluate the impact of their physical literacy interventions through physical literacy measures/assessments. To date, no systematic review has focused on empirical studies of physical literacy and the attempts made therein to measure/assess physical literacy.

\subsection{Purpose and Objectives}

The purpose of this systematic review was to collate and analyze empirical studies conducted on physical literacy and its related constructs, and to synthesize, and reflect on, current (up to 14 June, 2017) empirical measurement practice regarding physical literacy. Consequently, the aim will be met through the following two objectives:

1. To systematically review the empirical research and measurement/assessment attempts in relation to the concept of physical literacy and its related constructs (e.g., physical activity/health outcomes); and

2. To critically characterize, evaluate, and compare existing measures/assessments of physical literacy and its related constructs in relation to age group, environment, and philosophy.

\section{Methods}

The methodology of this article was adapted from that of Edwards et al.'s [4] systematic review on the definitions, foundations, and associations of physical literacy, which used the Preferred Reporting Items for Systematic Reviews and Meta-Analyses for Protocols (PRISMA-P) [60], and deployed thematic analysis for evaluating and organizing the findings.

\subsection{Information Sources and Search Strategy}

An electronic search strategy was deployed, using the following databases: (1) SPORTDiscus; (2) MEDLINE (via PubMed); (3) Scopus; (4) ScienceDirect; and (5) Education Research Complete, last searched on 14 June, 2017. The above databases report on areas including education, sport, and health, which are relevant to the concept of physical literacy and therefore increased the likelihood that all relevant studies were located [61, 62]. A Boolean logic combinations search strategy was adopted within the electronic databases, including "physical literacy" with measurement, assessment, charting, monitoring, evaluation, test, analysis, case study, practical, applied, intervention, trial, predictor, correlation, association, and relationship. Inverted commas were applied to the term "physical literacy" to ensure searches would find papers in relation to physical literacy as opposed to searches related to 'physical' and 'literacy'. English language, peer-reviewed, and journal filter boxes were marked on all searches to ensure only these papers would appear in the results [see Appendix S1 of the Electronic Supplementary Material (ESM)]. It was not possible to apply these filters or to use Boolean phrases in Google Scholar; therefore, the latter was not used in this study. Additional records were selected through identifying sources from the reference lists of the records identified through database searching [60].

\subsection{Eligibility Criteria and Study Records}

The inclusion criteria in this systematic review were as follows: (1) papers with a peer-reviewed published status; and (2) publications in the English language up until the date last searched: 14 June, 2017. To address the aims and objectives of the study, the following exclusion criteria were adopted: (1) papers not attempting to measure/assess attempts and/or empirical studies; (2) conference reports and readings; and, (3) editors' letters, forewords, and comments. The authors used the PRISMA-P evidencebased checklist during the planning, conduct analysis, and reporting of this process [60]. The PRISMA-P flow diagram for this study can be found in Fig. 1 and the PRISMA-P checklist can be found in Appendix S2 of the ESM [60].

A total of 671 papers were identified through database searches and an additional 50 records were retrieved from the reference lists in these 671 papers. In line with the PRISMA-P procedures, a total of 515 duplicated papers were removed during the search process, leaving 206 papers for the screening process. Non-duplicated papers 
Fig. 1 Preferred Reporting Items for Systematic Reviews and Meta-Analyses flow diagram [60]

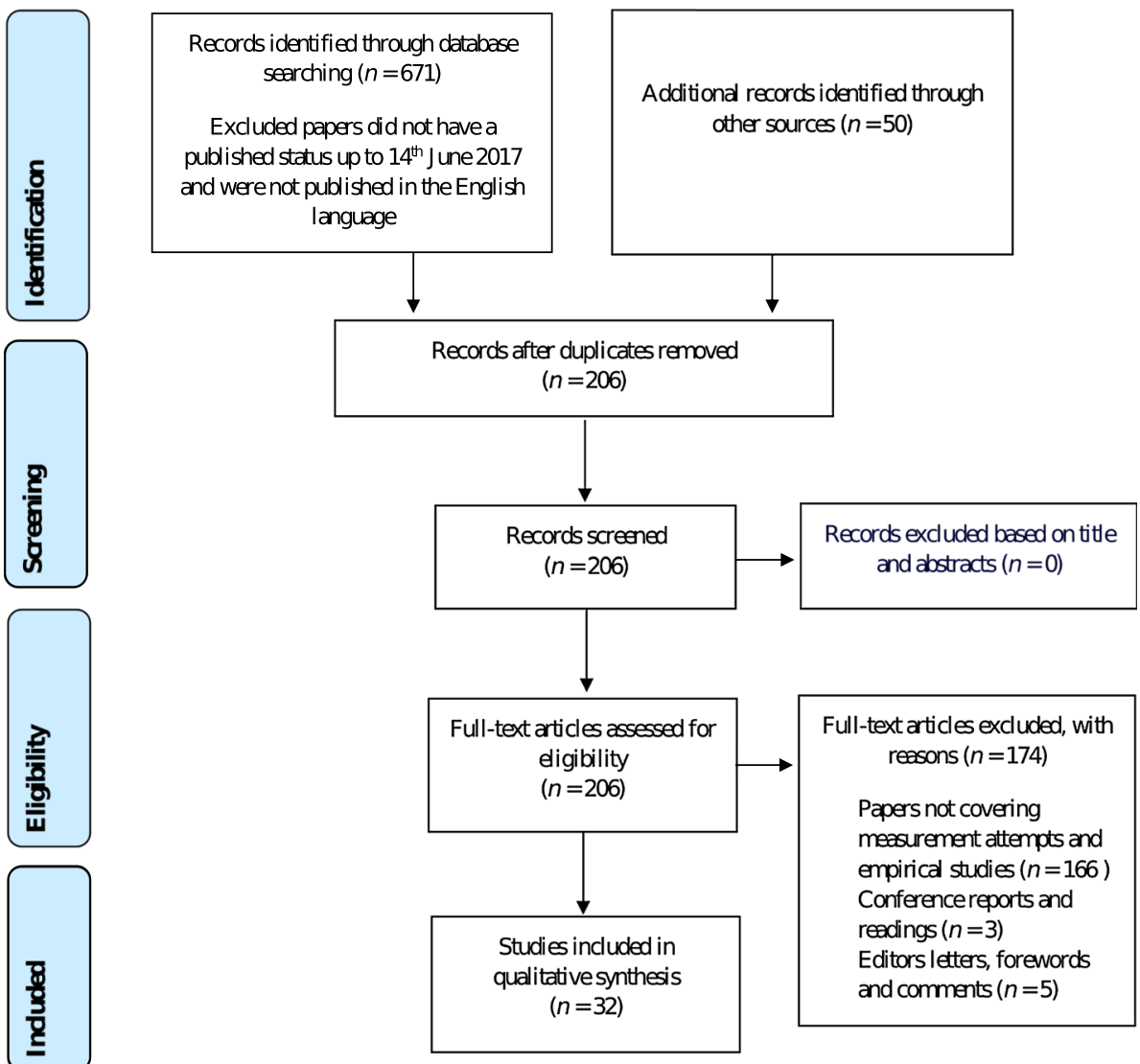

\subsection{Data Items and Data Synthesis}

the inclusion/exclusion criteria: in each case, mutual agreement was required between analysts [63]. To ensure consistency between analysts, a calibration exercise was conducted before commencing the data collection. During the selection process, the analysts uploaded their literature search results to a shared electronic file in an attempt to reduce publication and selection bias. Any discrepancies between the two analysts were resolved by consensus and/ or discussion with a third investigator. Records were kept of this process with an $89 \%$ agreement prior to discussion and a $100 \%$ agreement post-discussion. To assess the possible risk of bias in individual studies, the analysts adhered to the Cochrane Collaboration tool for assessing the risk of bias, which included identifying a low and high risk of bias for the following criteria: sequence generation, allocation concealment, blinding, incomplete outcome data, and selective outcome reporting [64]. During the data analyzing process, the following roles were adopted: (1) the analyst (who was also the first author; LE); (2) one coanalyst (AB); (3) one consensus validator (KM); (4) two internal critical friends (S-MC and AJ); and, (5) one external critical friend (RK). After this thorough process, and consistent with the exclusion and inclusion criteria, a total of 32 papers were included in the review (see Fig. 1).
Initially, inductive thematic analysis was employed to extract, label, and evaluate data from each paper. Characteristics including the author(s), definition of physical literacy used, philosophy adopted, outcome assessed, strengths and limitations of measures/assessment in relation to physical literacy and related constructs, age group, and environment were extracted from the 32 papers in the analysis (see Tables 2, 3, 4). The purpose of this process was to summarize the key features of each paper prior to conducting the thematic analysis. The process of thematic coding focused on unfolding both implicit and explicit ideas within the data [65]. Subsequently, qualitative synthesis using thematic analysis was performed on data from the 32 included papers. Thematic analysis was employed to distinguish common categories through analytical examination and recording themes within the 32 papers included in the analysis with the main purpose of data retrieval [66, 67].

To allow replication and transparency of data synthesis, a two-step process was performed. First, basic coding techniques to identify the general themes were completed, followed by interpretative coding that emphasized specific themes in the data [67]. This process comprised organizing 
Table 1 Thematic analysis of the measures/assessments of physical literacy and its related constructs

\begin{tabular}{|c|c|c|}
\hline Higher order themes & Sub-themes & Measures/assessments \\
\hline \multirow[t]{6}{*}{ Qualitative } & Interviews $(8)^{\mathrm{a}}$ & $\begin{array}{l}\text { Different environments (schools, universities, retirement homes) (5) } \\
\text { Determine the effectiveness of interventions (2) } \\
\text { Students' and teachers' perceptions of inclusive PE (1) }\end{array}$ \\
\hline & Open-ended questionnaires (4) & $\begin{array}{l}\text { Pupil attitude, opinion, and knowledge of PE (3) } \\
\text { Willingness of PE teachers to apply physical literacy (1) }\end{array}$ \\
\hline & Reflective diary (4) & $\begin{array}{l}\text { Teacher reflections on the effectiveness of PE (1) } \\
\text { Pupil reflections of food consumption (1) } \\
\text { Pupil reflections to set individual physical activity targets (1) } \\
\text { Student written responses to daily journal prompts (1) }\end{array}$ \\
\hline & Focus groups (4) & $\begin{array}{l}\text { Role of play in physical literacy from a child's perspective (1) } \\
\text { Students' perceptions of ability, disability, and inclusion in PE (1) } \\
\text { Retired people's understanding of physical literacy (1) } \\
\text { PE specialist primary and secondary teachers (1) }\end{array}$ \\
\hline & Participant observation (4) & $\begin{array}{l}\text { Children's interactions with the outdoor environment (2) } \\
\text { Social interactions between retired people (1) } \\
\text { Phenomenological observations of children (1) }\end{array}$ \\
\hline & Visual methods (8) & $\begin{array}{l}\text { Photo elicitation (2) } \\
\text { Video recordings (5) } \\
\text { Portfolio (1) }\end{array}$ \\
\hline Quantitative & Physical domain (31) & $\begin{array}{l}\text { Accelerometer (2) } \\
\text { Exergaming (2) } \\
\text { International Physical Activity Questionnaire (2) } \\
\text { Pedometer (4) } \\
\text { Postural tests (2) } \\
\text { 20-m multi-stage fitness test (1) } \\
\text { Anthropometric measures (2) } \\
\text { Bruininks-Oseretsky Test of Motor Proficiency (1) } \\
\text { FMS-Polygon (1) } \\
\text { Henderson and Sugden's Movement Assessment Battery for Children (1) } \\
\text { Agility test (2) } \\
\text { Non-validated battery of six motor tests (1) } \\
\text { Nutrition and Physical Activity Self-Assessment of Child Care (1) } \\
\text { Perceptions of Physical Activity Importance and their Children's } \\
\text { Ability Questionnaire (1) } \\
\text { Performance diary (1) } \\
\text { Physical Activity Questionnaire for Older Children (1) } \\
\text { System for Observing Fitness Instruction Time (1) } \\
\text { Straight sprint test (1) } \\
\text { Taco Bell Challenge (1) } \\
\text { Test of gross motor development (1) } \\
\text { The Canadian Agility and Movement Skills Assessment (1) } \\
\text { Vertical jump (1) }\end{array}$ \\
\hline
\end{tabular}


Table 1 continued

\begin{tabular}{ll}
\hline Higher order themes & Measures/assessments \\
\hline Affective domain (8) & Brustad's Children's Attraction to Physical Activity Scale (1) \\
& Children's Physical Activity Self-Efficacy Scale (1) \\
& Children's Self-Perception of Adequacy in and Predilection for Physical \\
& Activity Scale (1) \\
& Global Physical Self-Worth subscale of the Child and Youth Physical \\
& Self-Perception Profile (1) \\
& Harter's Self-Perception Profile for Children (1) \\
& Intrinsic Motivation Inventory (1) \\
& Non-validated affective questionnaire (1) \\
& Physical Ability subscale of the Self-Description Questionnaire (1) \\
Cognitive domain (5) & Creative thinking test (1) \\
& Mock exam paper (1) \\
& Non-validated cognitive questionnaire (1) \\
& Optional creative writing assignments (1) \\
& Understanding physical literacy questionnaire (1) \\
Physical, cognitive, & The Canadian Assessment for Physical Literacy (2)
\end{tabular}

FMS fundamental movement skills, $P E$ physical education

${ }^{a}$ Numbers in parenthesis represent the number of papers that referred to the core categories apparent out of a possible 32 papers

themes into: (1) two higher order themes; (2) ten subthemes; and (3) 52 measures/assessments (see Table 1) [66]. Table 1 displays the hierarchical structure that allows clear identification of the development from a core category to a sub-theme on to a higher order theme as well as identifying the frequency of each core category (i.e., how many papers referred to this item). The Grading of Recommendation, Assessment, Development and Evaluation approach was applied in the present study to provide a transparent guide on rating the quality of research [68]. This included incorporating appropriate items for qualitative synthesis under the following five headings: risk of bias, inconsistency, indirectness, imprecision, and publication bias [69].

\section{Results}

\subsection{Summary of Studies}

The papers that were identified, screened, and considered for eligibility are summarized in Fig. 1 [60]. Table 1 provides an overview of the core categories, sub-themes, and higher order themes that were evidenced from the analysis. Table 2 provides critical analyses of the qualitative measures/assessments used in the 32 studies in relation to physical literacy and its related constructs. Table 3 characterizes, evaluates, and compares existing qualitative measures/assessments of physical literacy and its related constructs in relation to age group, environment, and philosophy. Finally, Table 4 provides critical analyses of the quantitative measures/assessments.

Two higher order themes were distinguished: qualitative approaches and quantitative approaches. For the qualitative higher order theme, 19 core categories were evidenced under the following six subthemes: interviews, open-ended questionnaires, reflective diaries, focus groups, participant observation, and visual methods. For the quantitative higher order theme, 36 core categories were evidenced under the following four sub-themes: (1) physical domain; (2) affective domain; (3) cognitive domain; and (4) physical, affective, and cognitive domains (see Table 1).

As illustrated in Table 2, it was evident that $83 \%$ of qualitative papers used a Whiteheadian definition of physical literacy in their measures/assessments [42, 70-83]. The remaining $17 \%$ of papers measured/ assessed physical literacy by defining physical literacy as either: (1) developing literacy skills in a physical environment [84]; (2) developing physical competency skills [85]; (3) adopting the Physical and Health Education Canada definition [80]; or (4) not declaring a specific definition [86].

Overall papers measuring/assessing the physical domain were distributed reasonably equally across the different environments, namely: four measures/assessments took place in PE lessons [12, 42, 73, 87]; four in the community 


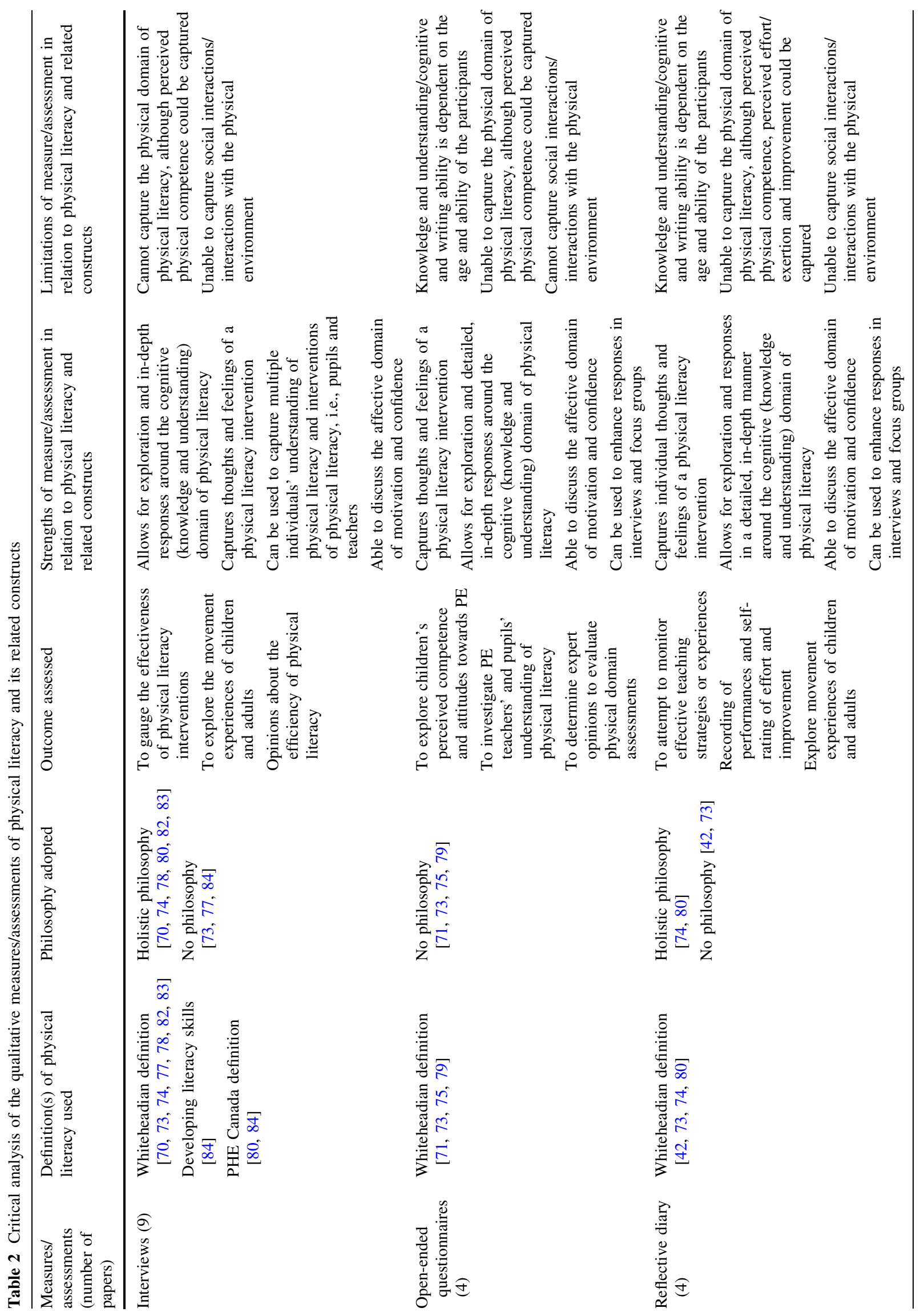




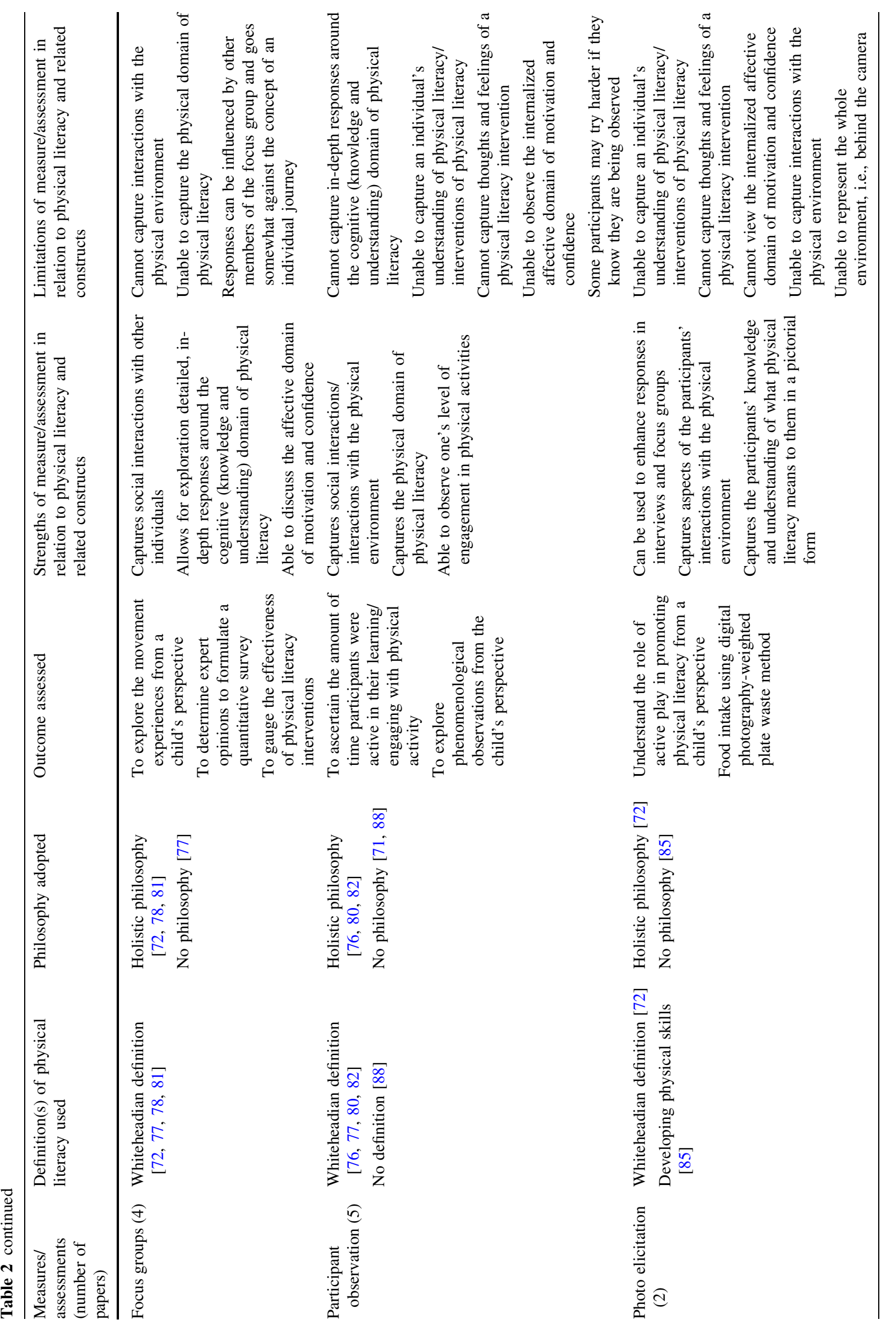




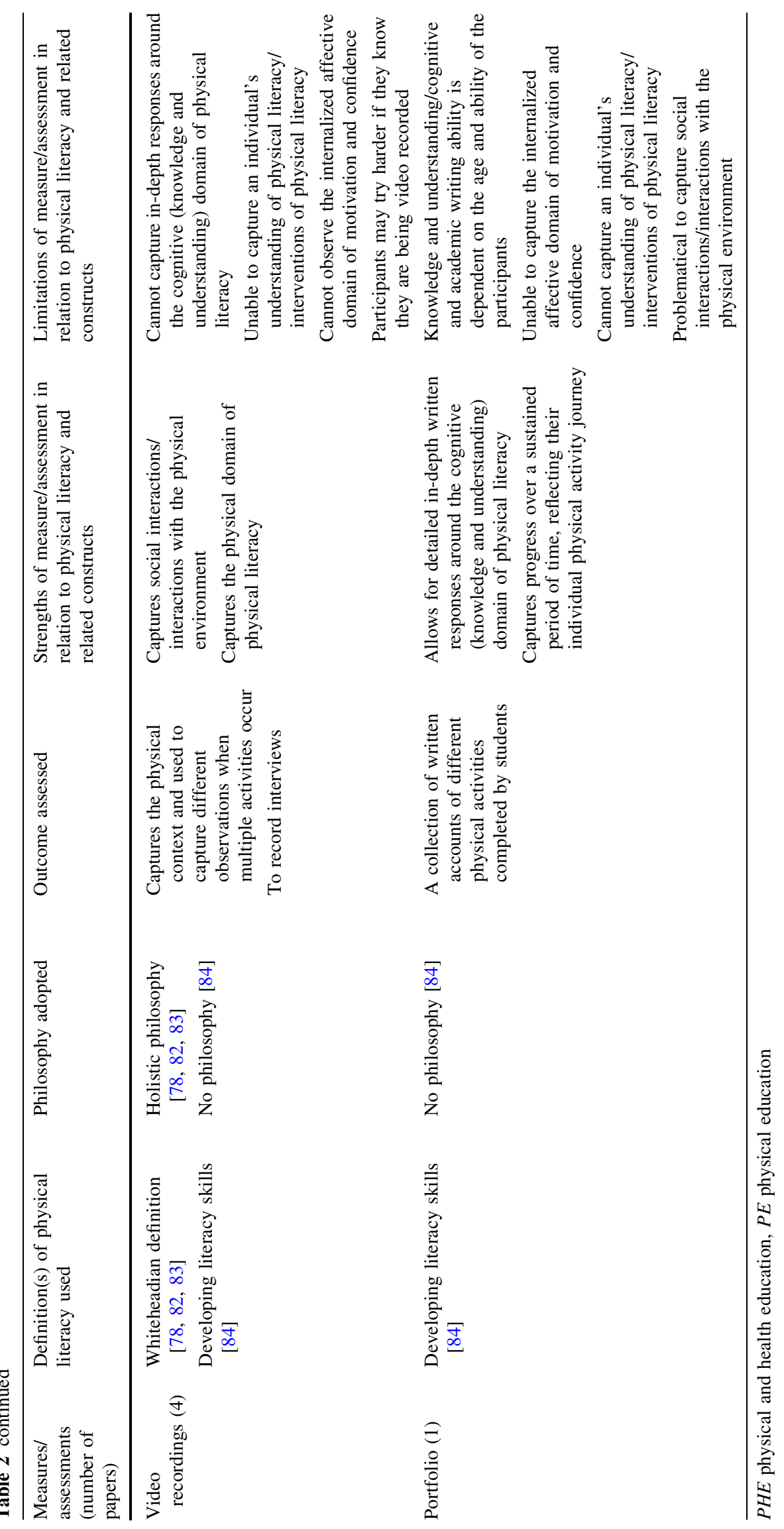


Table 3 Characteristics of the qualitative measures/assessments of physical literacy/related constructs characterized under age group, environment, and philosophy

\begin{tabular}{|c|c|c|c|c|c|c|c|c|c|}
\hline \multirow[t]{2}{*}{ Qualitative } & \multirow{2}{*}{$\begin{array}{l}\text { Papers } \\
(n)\end{array}$} & \multicolumn{3}{|c|}{ Age group } & \multicolumn{3}{|c|}{ Environment } & \multicolumn{2}{|c|}{ Philosophy } \\
\hline & & $\begin{array}{l}\text { Children } \\
\text { (U12) }\end{array}$ & Adolescents & Adults & $\mathrm{PE}$ & Community & Other & Holistic $^{\mathrm{a}}$ & $\begin{array}{l}\text { No declared } \\
\text { philosophy }\end{array}$ \\
\hline Interviews & 9 & 5 & 2 & 3 & 6 & 1 & 2 & 6 & 3 \\
\hline Open-ended questionnaires & 4 & 2 & 1 & 1 & 3 & 0 & 1 & 0 & 4 \\
\hline Reflective diary & 4 & 4 & 0 & 0 & 2 & 1 & 1 & 2 & 2 \\
\hline Focus groups & 4 & 1 & 0 & 3 & 2 & 0 & 2 & 3 & 1 \\
\hline Participant observation & 5 & 3 & 1 & 2 & 3 & 1 & 1 & 3 & 2 \\
\hline Photo elicitation & 2 & 2 & 0 & 0 & 0 & 0 & 2 & 1 & 1 \\
\hline Video recordings & 4 & 1 & 2 & 1 & 3 & 0 & 0 & 3 & 1 \\
\hline Portfolio & 1 & 0 & 1 & 0 & 1 & 0 & 0 & 0 & 1 \\
\hline
\end{tabular}

$P E$ physical education, $U 12$ under 12 years of age

${ }^{a}$ Holistic philosophy included authors using one or more of the following keywords: whole person, phenomenology, existentialism, monism, holistic

[76, 88-90]; and five in other environments [41, 85, 91-93] (see Table 4). Four measures/assessments of the affective domain were conducted within PE lessons [42, 71, 74, 87] and one measure/assessment in the community [89]. Two measures/assessments of the cognitive domain were undertaken within PE lessons [74, 86]: two in the community [80, 90] and one in a research-based environment [79].

\section{Discussion}

There is limited empirical research that has attempted to measure/assess physical literacy to date. Papers that included any element of physical literacy and its related constructs, such as physical activity, were therefore included in the analysis. The analysis identified a total of 78 codes, which were organized into 55 core categories and ten sub-themes. These were then organized into two higher themes to address the study's aims and objectives. The following section will review these two higher themes: qualitative and quantitative measures/assessments.

\subsection{Qualitative Measures/Assessments}

Many qualitative methods allowed researchers to gain indepth responses to measure/assess the cognitive and/or affective domains of physical literacy. For example, interviews, open-ended questionnaires, reflective diaries, focus groups, and portfolios could measure/assess individuals' motivation and confidence towards participating in physical activity, as well as provide opportunities to gauge knowledge and understanding of physical activity and healthy lifestyle behaviors [4]. Interviews, open-ended questionnaires, reflective diaries, focus groups, and portfolios were, however, unable to measure/assess an individual's physical competence as they are reliant on self-perceptions and/or perceptions of others [70, 73, 74, 77, 78, 80, 82-84]. Indeed, aside from participant observation and video recordings, there were very few qualitative methods that measured/assessed the physical domain of physical literacy [76-78, 80, 82-84, 94]. Using a range of qualitative methodologies and considering all three domains (physical, affective, and cognitive) could address limitations in measuring/assessing physical literacy in a holistic manner [95]. Nonetheless, a crucial point in determining strengths and limitations of qualitative research is the role and quality of the researcher [96]. The interpretive nature of qualitative research could influence the strengths and limitations of methods/results and instigate bias; therefore, caution is required when solely relying on qualitative data.

Another prominent aspect of physical literacy was the social element, i.e., social interactions with peers in the physical environment [15]. Its prominence in physical literacy has prompted some scholars to view 'social' as the fourth domain of physical literacy [97]. Some qualitative methods could be used to measure/assess social interactions with peers, namely, focus groups, participant observations, and video recordings. A critique of the current literature is that no measure/assessment to date has attempted to capture the social domain. Nevertheless, some qualitative methods captured interactions with the physical environment, to capture individuals' responses to "the embodied needs of the perceived environment" (participant observation and video recordings) [15], though most qualitative methods could not capture interactions with the physical environment (interviews, open-ended questionnaires, reflective diaries, focus groups, and photo elicitation) $[76-78,80,82-84,94]$. Social interactions and 


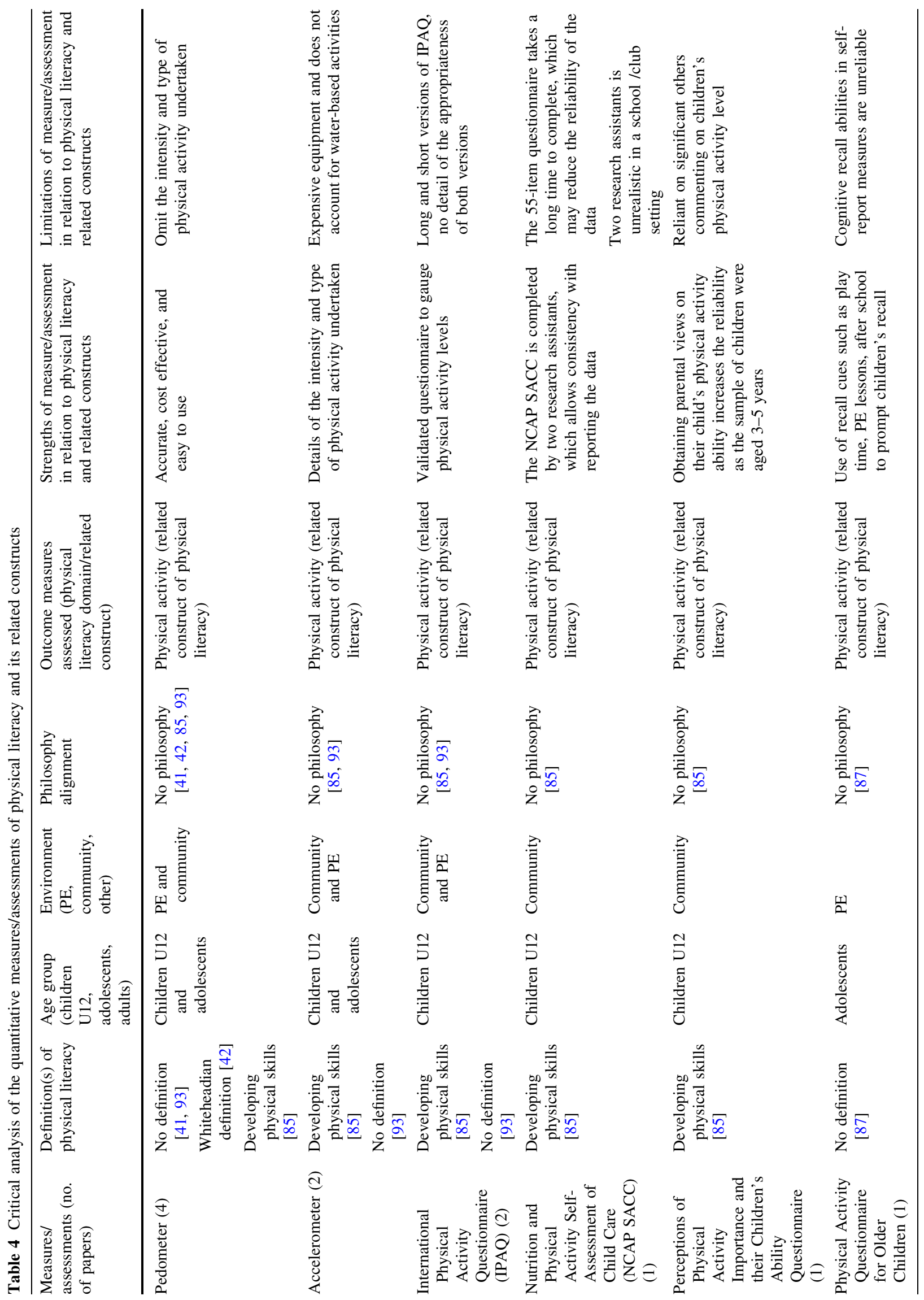




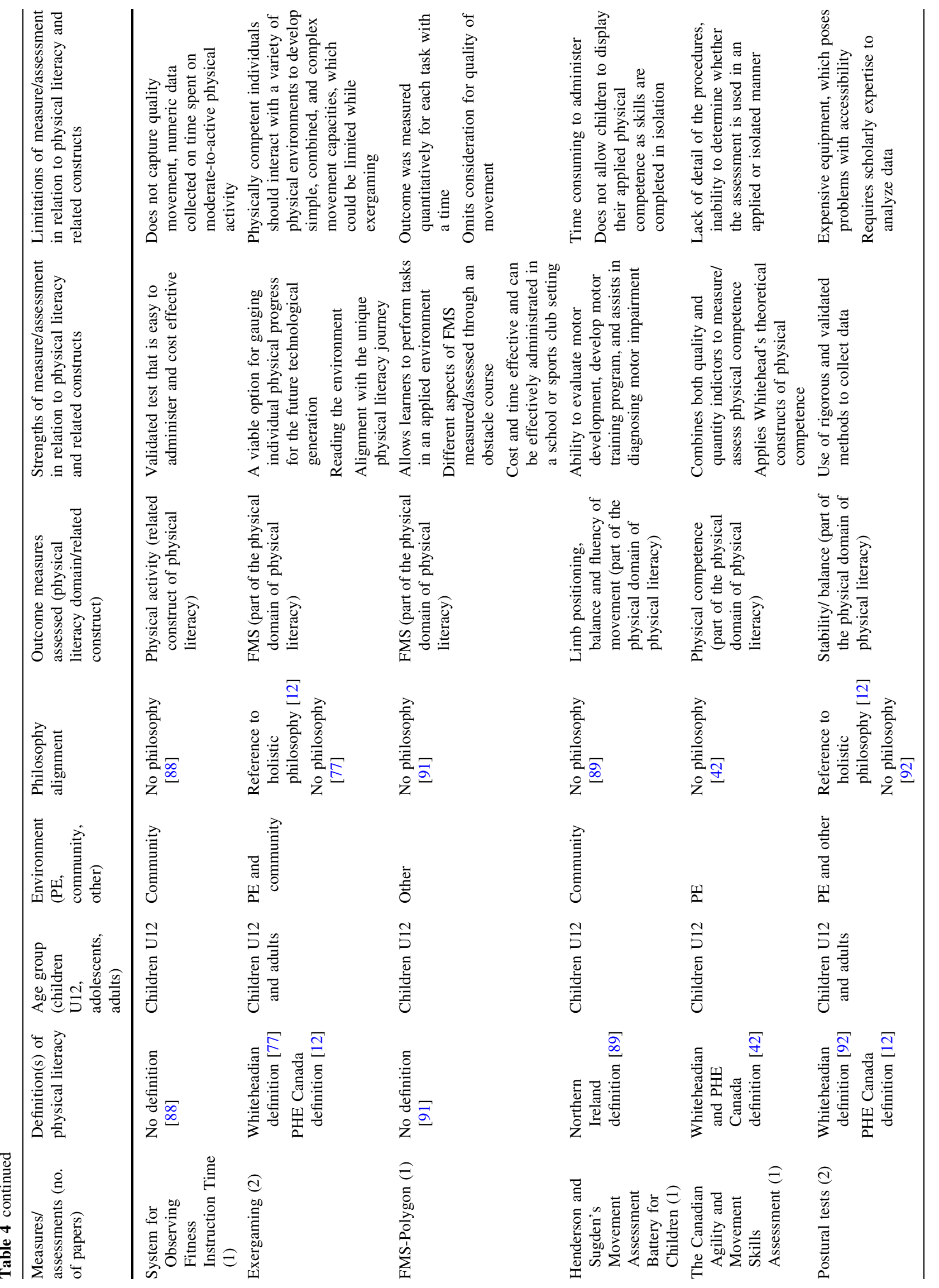




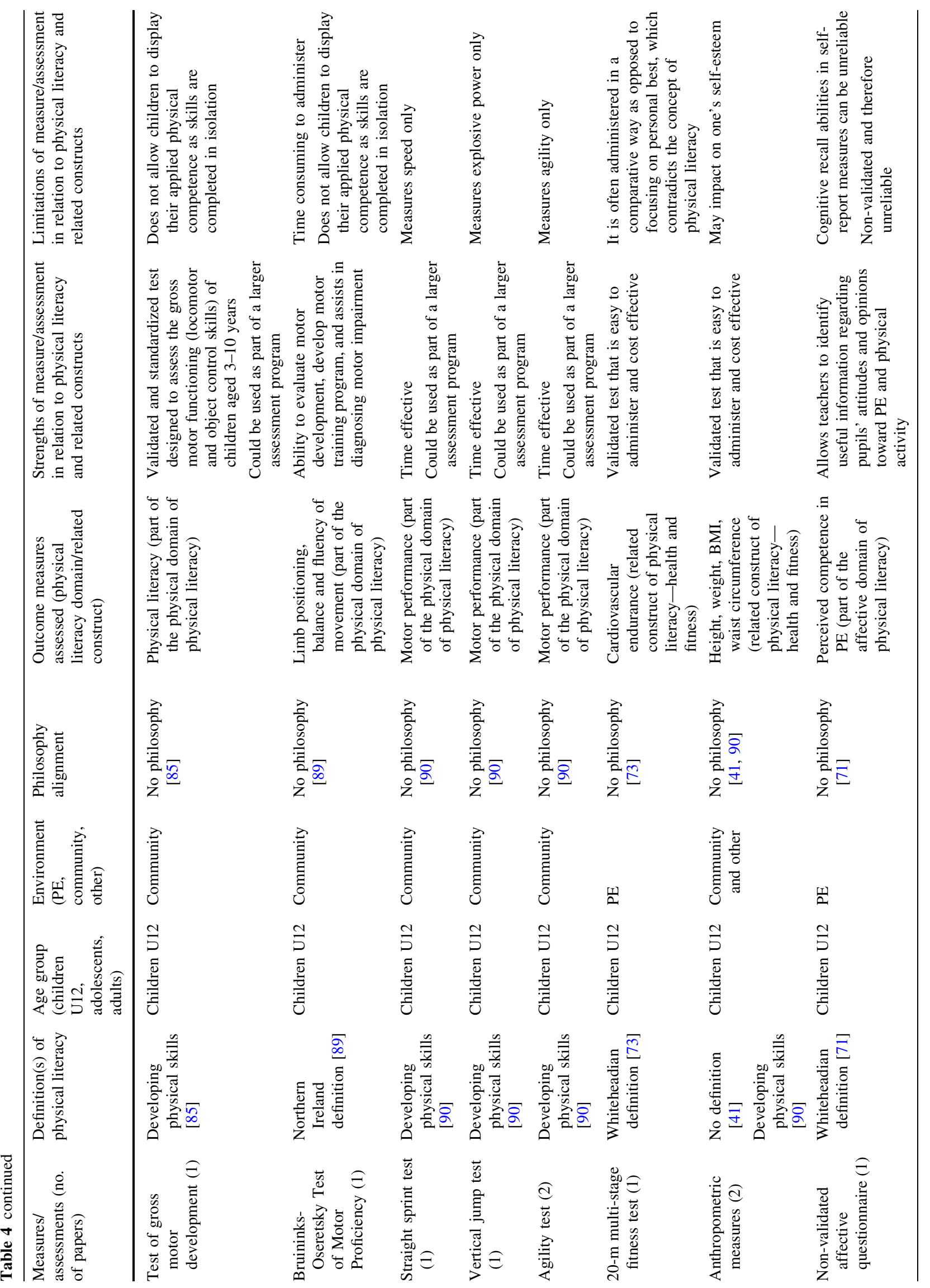




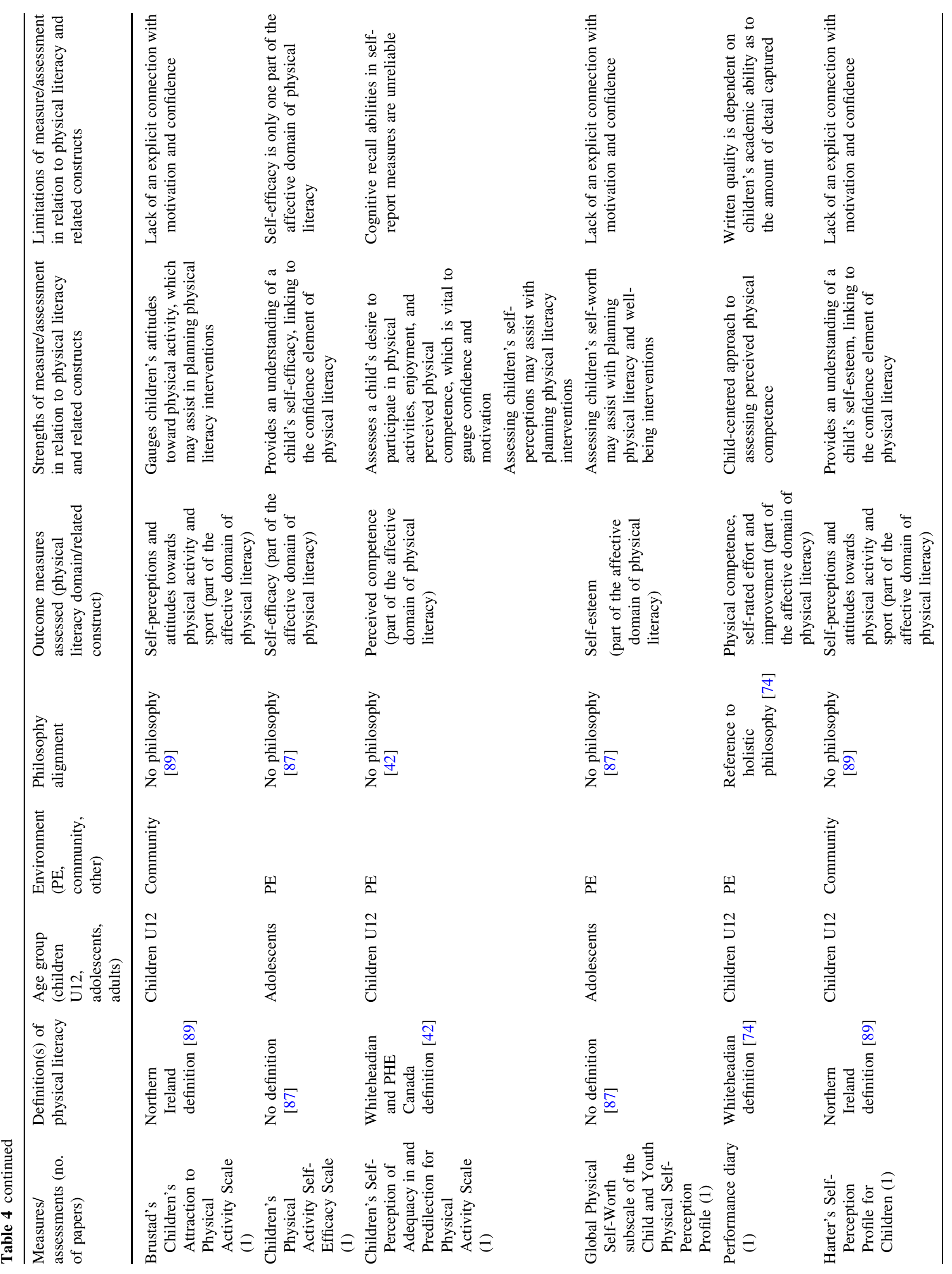




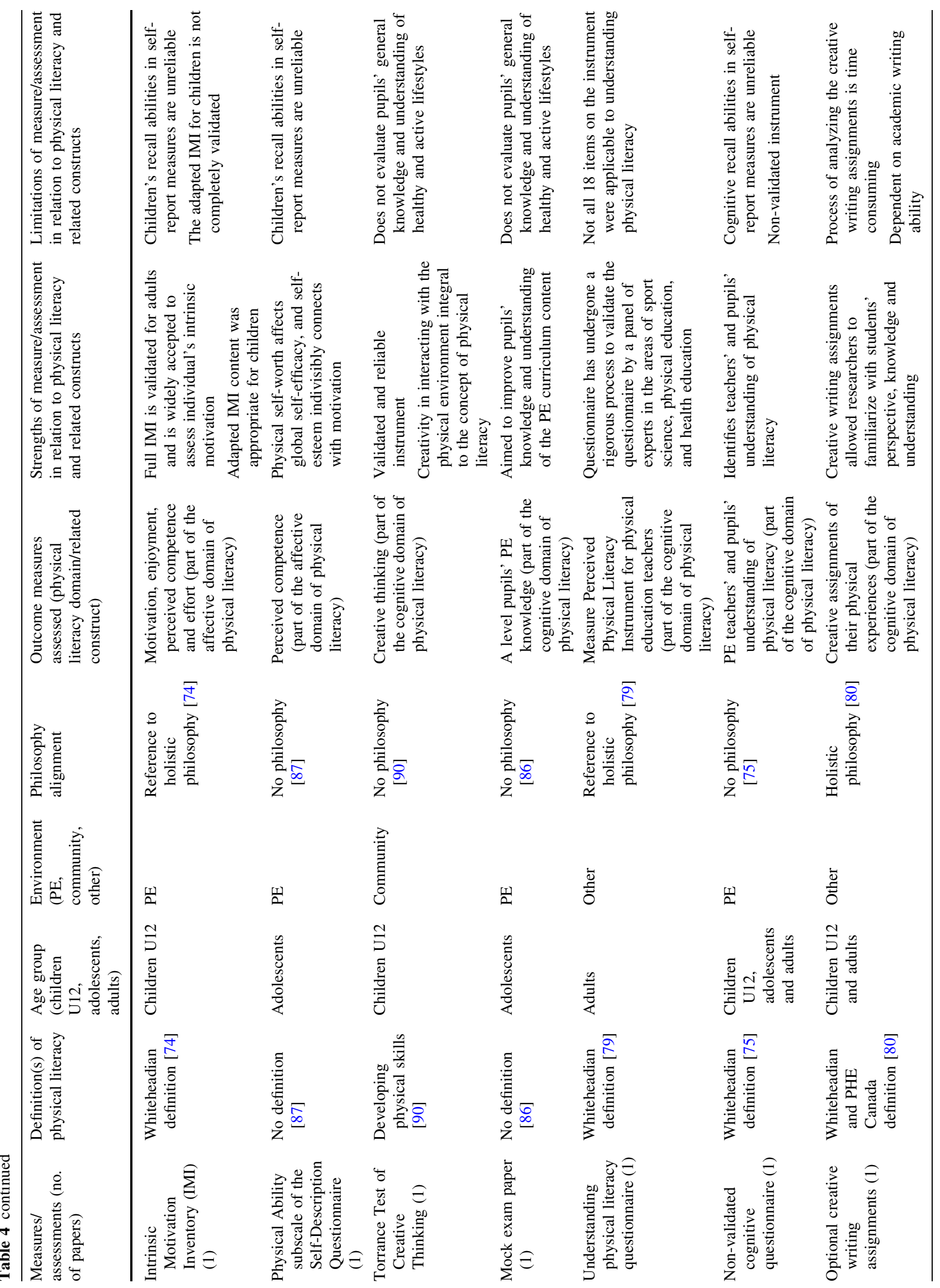




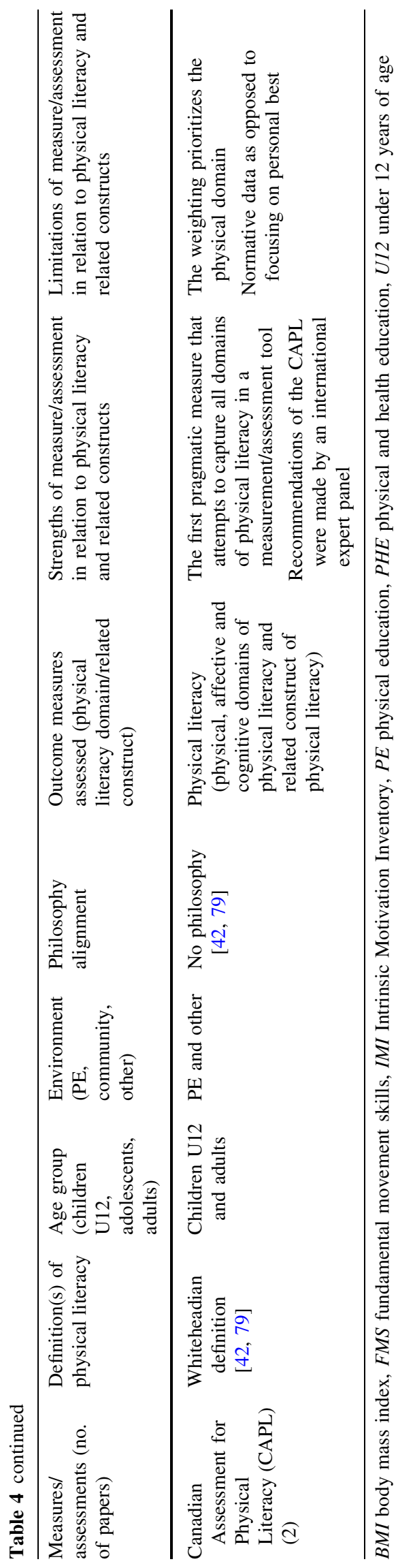

interactions with the environment are central to the phenomenological and existential philosophical underpinnings of the concept, as the richer one's interactions with the environment, the greater one will understand and reach their human potential $[4,98,99]$. As such, using qualitative methods to measure/assess these interactions as part of the wider physical literacy concept attempts to retain the integrity of its holistic nature.

Overall, interviews, focus groups, participant observation, and video recordings were predominantly holistic in their philosophy, whereas open-ended questionnaires and portfolios did not declare a philosophy. More qualitative papers adopted a holistic philosophy, purportedly drawing from phenomenology, monism, and existentialism $(n=18)$ as opposed to not declaring their philosophical assumptions $(n=15)$. In this review, the adoption/declaration of a holistic philosophical standpoint was dependent on the individual studies as opposed to the specific qualitative methodology. To achieve alignment between the definition, philosophy, and outcome measure/assessment, researchers working within physical literacy should be explicit about the definition and philosophy they adopt.

Significantly more qualitative papers measured/assessed physical literacy with children under 12 years of age, compared with adolescents and adults (children aged under 12 years, $n=18$; adolescents, $n=7$; adults, $n=10$ ). A likely reason for more measures/assessments in children aged under 12 years may be the opportunistic research strategies, as children aged under 12 years are readily accessible in a school environment. The results of the analysis suggest that interviews, reflective diaries, photo elicitation, and participant observation were highly suitable for children aged under 12 years (see Table 3) $[42,70,72-74,76,80,82,85]$. These qualitative measures/ assessments are suitable because they are individualized, which permits a non-comparative experience, thus aligning with the holistic nature of the physical literacy concept and a mastery motivational climate, which emphasizes selfreferenced improvement and personal progress as the criteria for success [100].

Nonetheless, children/adolescents' thoughts and feelings are unpredictable and could change on a daily basis, making it challenging to effectively measure/assess the affective and cognitive domains of physical literacy with qualitative measures/assessments alone. Conversely, openended questionnaires, focus groups, and video recordings were not as appropriate for children aged under 12 years [71-73]. Written forms of data such as open-ended questionnaires may elicit in-depth responses from children; however, they are reliant on the academic ability of the child. Therefore, careful consideration of the age/ability of each child is required to determine the appropriateness of open-ended questionnaires. Similarly, the use of video 
recordings to assess physical competence and interactions with the environment is reliable [101]; however, researchers may face many safeguarding and ethical barriers to video recording children aged under 12 years, as well as a change in normal behavior if children are aware that they are being recorded [82]. This suggests that alternative qualitative measures/assessments of physical competence that are less invasive, such as participant observation, may be more appropriate for children aged under 12 years and adolescents [76, 80, 82].

The analysis revealed that the dominant environment to qualitatively assess physical literacy was during PE lessons ( $n=12$ papers) $[42,71,73-75,77,78,81-84,94]$. One paper assessed physical literacy in a community sports club setting [80] and five papers assessed physical literacy in 'other' environments such as care homes for the elderly, nurseries, and unstructured physical activity/play settings $[70,72,77,79,85]$. Given the assessment-based culture in educational settings, it is unsurprising that PE lessons are the dominant environment to empirically measure/assess physical literacy qualitatively. Nonetheless, as the concept of physical literacy extends over the life course, it is problematic that the vast majority of qualitative research is concentrated within a school environment. More qualitative research with young adults, adults, and elderly citizens in different environments is required to better operationalize the concept over the life course.

\subsection{Quantitative Measures/Assessments}

In contrast to qualitative measures/assessments, the definition of physical literacy adopted by quantitative measures/assessments varied: $29 \%$ of measures/assessments used Whitehead's definition [42, 71, 73-75, 77, 79, 80, 92]; $29 \%$ declared no definition [41, 86-88, 91, 93]; $24 \%$ defined physical literacy as developing physical skills [85, 89]; 9\% adopted the Physical Health Education Canada definition $[12,42,80]$; and a further $9 \%$ used Northern Ireland's definition [89].

Under the physical domain, two quantitative measures/ assessments adopted a holistic philosophy [12], whereas the other 19 quantitative measures/assessments under the physical domain declared no philosophy [41, 42, 73, 77, 85, 87-93]. Under the affective domain, significantly fewer quantitative measures/assessments adopted a holistic philosophy $(n=1)$ [74] compared with no declared philosophy $(n=7)$ [42, 71, 87, 90]. Under the cognitive domain, four measures/ assessments did not declare a philosophy [75, 79, 86, 90] and one declared a holistic philosophy [80]. Overall, there was an assumption that the philosophical approach in quantitative research was positivism; however, the majority of quantitative measures/assessments did not declare their philosophical standpoint. In turn, most quantitative studies did not align with the holistic philosophy. For example, most measures/assessments in the physical domain evaluated physical competence, FMS, and motor capacities in isolation instead of in applied settings [42, 89, 90, 92] with the exception of the FMSPolygon [97].

Further, quality of movement was often not measured/ assessed in the quantitative studies that captured the physical domain; tests were usually timed, which was problematic for the following two reasons. First, solely timing a test as the main measure omits the opportunity for quality of movement to be captured. Second, these types of times tests have the potential to create a comparative environment if administered in the incorrect manner [42, 73, 85, 90-92]. Consequently, this contradicts the philosophical underpinnings of the concept as there should be a concentration on individualized ability and progress [15]. Separating the individual domains of physical literacy (physical, affective, and cognitive) to measure/assess physical literacy arguably refutes the 'holistic' philosophical underpinnings of the concept. Thus, it would be important for those invoking an integrated holistic philosophy to physical literacy to specify how their measurement approaches acknowledge and accommodate this core assumption.

Similar to the findings in the qualitative measures/ assessments subsection, children aged under 12 years were the leading age group studied most often under the physical domain with a total of nine quantitative measures/assessments [12, 41, 42, 73, 85, 88-91]. Adolescents [87, 93] and adults [76, 92] had two quantitative measures/assessments, respectively, under the physical domain. Further, more quantitative papers measured/assessed the affective domain of physical literacy in children aged under 12 years $(n=4)$ compared with adolescents $(n=1)$ and adults $(n=0)$ [42, 71, 74, 87, 89]. Children aged under 12 years $[75,80,90]$ and adults $[75,79,80]$ were the dominant age groups under the cognitive domain with three quantitative measures/assessments, respectively, compared with two measures/assessments with adolescents [75, 86].

Though there are limitations with recall in self-report measures with children, many quantitative measures/ assessments across physical, affective, and cognitive domains were judged to be reliable [42, 85, 87-90, 93]. A generic quantitative measure/assessment of physical literacy is not favorable as it would be challenging to integrate all domains and make it relevant for different sports/activities. For example, physical activity for elderly citizens may include gardening, thus a validated tool of their motor proficiency and a questionnaire on their attitude towards physical activity would not provide an accurate representation of their physical literacy journey. Attempting to develop quantitative tools that specify validated 'ages' leads to further debate surrounding their appropriateness 
for physical literacy as the 'stage not age' concept departs from normative assessment strategies, which are often employed in the quantitative research measures/assessments [15, 85, 90, 91].

Many quantitative measures/assessments are cost/time effective and easy to administer; therefore, they would be accessible in a variety of different environments (PE/community/other) [41, 42, 73, 85, 93]. Given the recent demand on schools to continually assess learners' progress, adopting quantitative measures/assessments may help teachers track pupil progress, identify areas for development, and plan interventions tailored to each learner [102]. Using assessment for learning strategies to achieve this would provide a greater focus on formative, as opposed to summative assessment strategies, which is consistent with high-quality PE [103]. Further, quantitative research may evidence the effectiveness of these physical literacy interventions, which in turn may generate funding to conduct further impactful research. Nonetheless, many practitioners would argue that administering and analyzing measures/assessments of physical literacy is unrealistic in educational settings because of teachers' time constraints, and the current priority of literacy and numeracy $[104,105]$. For a viable change to occur on the ground, more accountability for physicality and physical literacy is required in schools so that teachers prioritize physical literacy alongside literacy and numeracy. That said, teachers engaging with the concept of physical literacy should be reminded and assured that measuring/assessing physical literacy quantitatively is not the quintessential component of the concept: i.e., the pedagogical processes that generate motivated, confident, and knowledgeable learners are imperative to engage children in physical activity throughout the life course [106]. If practitioners use measures/assessments without consideration for pedagogy, they are likely to disengage children, thus contradicting the key purpose of the concept [15]. Penney et al. [107], drawing on Bernstein's [108] conceptualization of curriculum, argue for the inter-relationship between curriculum, assessment, and pedagogy as a fundamental dimension of quality PE.

The results and discussion clearly demonstrate a scarcity of measures/assessments that attempt to capture the entire range of domains within physical literacy, and/or treat it as an integrated construct across these domains. To date, only one measure/assessment (Canadian Assessment for Physical Literacy) has attempted to collectively measure/assess three domains of physical literacy (physical, affective, and cognitive). Three potential reasons for the limited measures/assessments of physical literacy include: (1) researchers are yet to discover measures/assessments that align with their definition and philosophy of physical literacy; (2) researchers are yet to discover the appropriate physical literacy measures/assessments for the age and/or environment; and, (3) the complex and multifaceted physical literacy concept poses challenges to researchers on how it is best operationalized. Adding to this complexity, the results of the present systematic review indicate that researchers are yet to consider the social domain within measures/assessments of physical literacy. As such, our analysis revealed that by adopting simplistic and linear methods, physical literacy cannot be measured/assessed in a traditional/conventional sense. In this context, there is a need for more creative approaches to measure/assess physical literacy through non-conventional methods. Future research should therefore consider the more recent developments by Dudley et al. [16] in the field for physical literacy policy formation in the public health, recreation, sport, and education sectors.

\subsection{Limitations}

Papers in the English language were solely considered for this systematic review; thus, the papers were primarily derived from the UK and Canada, which may be considered as a limitation. Owing to the limited empirical research on the concept of physical literacy, the 32 papers included in the present study encompassed both physical literacy and its related constructs, such as physical activity. Caution should be exercised when assessing the papers that measure/assess the related constructs of physical literacy. These papers should not be considered as the sole method to measure/assess physical literacy, but used in conjunction with explicit physical literacy assessments. Nevertheless, future empirical research and attempts to measure/assess physical literacy will significantly contribute to the field of physical literacy.

\section{Conclusions}

This paper is the first to provide a systematic review of empirical research efforts to measure or assessment physical literacy, and is the first to systematically reveal that the concept cannot be measured/assessed in a traditional and conventional sense using simplistic and linear methods. This systematic review has identified the strengths and limitations of both qualitative and quantitative approaches to measuring/assessing physical literacy in relation to age group, environment, and philosophy adopted [4]. Quantitative measures/assessments more readily facilitate judgments of reliability, validity, and replicability; however, they are less aligned with physical literacy's holistic philosophy as defined by Whitehead [14]. Consequently, researchers should declare their definition and philosophy to create an alignment with the measure/assessment 
selected. Qualitative research aligned more with the holistic philosophical underpinnings of phenomenology, existentialism, and monism than did quantitative research. Qualitative measures/assessments allowed researchers to measure/assess the complex and integrated phenomena, such as interactions with the physical environment, which may lead to more legitimate attempts to quantify physical literacy holistically. Overall, qualitative methods of inquiry have more potential to measure/assess the affective and cognitive domains than the physical domain of physical literacy. As identified by the present analysis, no currently available qualitative technique can adequately measure/ assess all physical literacy domains, particularly in a way that reflects the integrated non-linear nature of the concept. Therefore, a combination of methods is required to better characterize overall physical literacy progress. Some qualitative measures/assessments captured interactions with the environment and interactions with other individuals, which cannot be captured in quantitative research. In both qualitative and quantitative measures/assessments, children aged under 12 years and PE lessons were the dominant age range and environment to measure/assess physical literacy.

An implication for theory development within physical literacy is the need for researchers to declare their definition and philosophical standpoint whilst undertaking empirical research, to ensure alignment between the definition, philosophy, and measure/assessment adopted. Identifying a philosophical standpoint would enable researchers to "operationalize the related construct of physical literacy and establish meaningful, measureable differences" [4]. Without this, it is problematic for practitioners to fully decipher how best to apply and measure/ assess the concept of physical literacy. Hence, consideration of the definition and philosophical groundings is required to ensure the methods of measuring/assessing physical literacy are suitable for research purposes, i.e., to identify the effectiveness of an intervention. Many of the measures/assessments, across all domains, require a level of expertise while administrating and analyzing, which may be problematic in school and community-based settings $[12,86]$. Further, some measures/assessments may require accompanying training to ensure the pedagogical processes are appropriate. For example, in an educational context, teachers conducting measures/assessments of the physical domain promoting a comparative environment may be detrimental to a pupil's physical literacy progress. Practitioners should first concentrate on the process of applying high-quality pedagogy to reflect their definition and philosophy of physical literacy, before assessing the outcomes (measures/assessments) [109]. The pedagogical principles consistent with high-quality practical delivery in PE have been identified by Morgan [110] using Ames'
[100] interpretation of Epstein's [111] work on developing effective learners. Specifically, Morgan [110] argues that the pedagogical principles identified by creating a mastery motivation are consistent with the holistic concept of physical literacy and high-quality PE.

Similarly, to apply high-quality pedagogy to foster physical literacy, practitioners should also consider creating a caring climate [112], empowering climate [113], and motivational atmosphere [114].

Recommendations for future research include a need for more empirical research on the concept of physical literacy; essentially, there is a need for more research that is open about the definition and philosophical approach used and theories tested. Future research should measure/assess beyond the constructs of physical proficiencies, and aim to measure/assess physical literacy from a more holistic perspective. Further, research across all ages and different environments is required; current research is predominantly constrained to children and youth in PE lesson settings with a minority measuring/assessing physical literacy in young adults, adults, and the elderly.

\section{Compliance with Ethical Standards}

Funding No sources of funding were used to assist in the preparation of this article.

Conflict of interest Lowri C. Edwards, Anna S.Bryant, Richard J. Keegan, Kevin Morgan, Stephen-Mark Cooper, and Anwen M. Jones have no conflicts of interest directly relevant to the content of this review.

Open Access This article is distributed under the terms of the Creative Commons Attribution 4.0 International License (http:// creativecommons.org/licenses/by/4.0/), which permits unrestricted use, distribution, and reproduction in any medium, provided you give appropriate credit to the original author(s) and the source, provide a link to the Creative Commons license, and indicate if changes were made.

\section{References}

1. Keegan RJ, Keegan SL, Daley S, et al. Getting Australia moving: establishing a physically literate \& active nation (game plan). Canberra: University of Canberra; 2013.

2. Jurbala $P$. What is physical literacy, really? Quest. 2015;67(4):367-83.

3. Gately P. Physical literacy and obesity. In: Whitehead M, editor. Physical literacy: throughout the lifecourse. Oxon: Routledge; 2010. p. 83-99.

4. Edwards LC, Bryant AS, Keegan RJ, et al. Definitions, foundations and associations of physical literacy: a systematic review. Sports Med. 2017;47(3):113-26.

5. Delaney B, Donnelly P, News J, et al. Improving physical literacy. Belfast: Sport Northern Ireland; 2008. 
6. Tremblay M. Major initiatives related to childhood obesity and physical inactivity in Canada: the year in review. Can J Public Health. 2012;103(3):164-9.

7. Schools and Physical Activity Task and Finish Group. Physical literacy: an all-Wales approach to increasing levels of physical activity for children and young people. Cardiff: Crown; 2013.

8. Liebenson C. Training for speed. J Bodyw Mov Ther. 2009;13(4):362-3.

9. Caput-Jogunica R, Lončariž D, De Privitellio S. Extracurricular sports activities in preschool children: impact on motor achievements and physical literacy. Croat Sports Med J. 2009;24(2):82-8.

10. Almond L. Physical literacy and fundamental movement skills: an introductory critique. ICSSPE Bull J Sport Sci Phys Educ. 2013;65:80-8.

11. Sheehan D, Katz L. The pursuit of physical literacy: can exergaming develop fundamental movement skills like balance? Can J Diabetes. 2011;35:174.

12. Sheehan D, Katz L. The impact of a six week exergaming curriculum on balance with grade three school children using the Wii FIT + TM. Int J Comput Sci Sport. 2012;11(3):5-22.

13. Physical and Health Education Canada. Physical literacy. 2010. Available from: http://www.phecanada.ca/programs/physicalliteracy/what-physical-literacy. Accessed 16 June 2017.

14. Whitehead M. International Physical Literacy Association: physical literacy definition. 2016. Available from: http://www. physical-literacy.org.uk/. Accessed 11 Feb 2016.

15. Whitehead M. Physical literacy: throughout the lifecourse. Oxon: Routledge; 2010.

16. Dudley D, Cairney J, Wainwright N, et al. Critical considerations for physical literacy policy in public health, recreation, sport, and education agencies. Quest. 2017. https://doi.org/10. 1080/00336297.2016.1268967.

17. Hylton K. Physical literacy, 'race' and the sociological imagination. ICSSPE Bull J Sport Sci Phys Educ. 2013;65:223-7.

18. Blaikie NWH. Approaches to social inquiry. Cambridge: Policy Press; 1993.

19. Godfrey-Smith P. Theory and reality: an introduction to the philosophy of science. Chicago: University of Chicago Press; 2003.

20. Huitt W, Hummel J, Kaeck D. Assessment, measurement, evaluation, and research: educational psychology interactive. Valdosta: Valdosta State University; 2001.

21. Trochim W, Donnelly JP, Arora K. Research methods: the essential knowledge base. Boston: Cengage Learning; 2014.

22. Sufian AJM. Methods and techniques of social research. Int $\mathrm{J}$ Bus Stat Anal. 2015;2(2):91-7.

23. Belli G. Nonexperimental quantitative research. In: Lapan SD, Quartaroli MT, editors. Research essentials: an introduction to designs and practices. San Francisco: Jossey-Bass; 2009. pp. 59-77. Available from: http://www.k4health.org/sites/ default/files/migrated_toolkit_files/0470181095-1.pdf. Accessed 11 Feb 2016.

24. Dennett DC. Darwin's dangerous idea: evolution and the meanings of life. New York: Simon and Schuster; 1995.

25. Whitehead M. The concept of physical literacy. Br J Teach Phys Educ. 2001;32(1):6-8.

26. Kuhn TS. The structure of scientific revolutions. Chicago: University of Chicago Press; 1962.

27. Rorty R. Philosophy and the mirror of nature. Oxford: Blackwell Publishers; 1980.

28. Hassmén P, Keegan R, Piggott D. Rethinking sport and exercise psychology research. London: Palgrave Macmillan UK; 2016.

29. Hume D. An inquiry concerning human understanding. London: T. Cadell; 1748.
30. Popper KR. The logic of scientific discovery. New York: Harper; 1959.

31. Popper KR. Conjectures and refutations: The growth of scientific knowledge. London: Routledge \& Kegan Paul; 1969.

32. Simmel G. Essays on interpretation in social science. Totowa: Rowman and Littlefield; 1980.

33. Gergen K. Realities and relationships: soundings in social construction. Cambridge: Harvard University Press; 1994.

34. Gergen K, Hoffman L, Anderson H. Is diagnosis a disaster? A constructionist dialogue. In: Kaslow F, editor. Handbook for relational diagnosis. New York: Wiley; 1996. p. 102-20.

35. Gergen M, Gergen K. Qualitative inquiry, tensions and transformations. In: Denzin N, Lincoln Y, editors. The landscape of qualitative research: theories and issues. Thousand Oaks: SAGE; 2000. p. 1025-46.

36. Bhaskar RA. Realist theory of science. London: Verso; 1975.

37. Bhaskar RA. Reclaiming reality: a critical introduction to contemporary philosophy. London: Verso; 1989.

38. Bartley WW. The retreat to commitment. 2nd ed. LaSalle: Open Court; 1984.

39. Munz P. Our knowledge of the growth of knowledge: Popper or Wittgenstein?. London: Routledge; 1985.

40. Higgs C. Physical literacy: two approaches, one concept. Phys Health Educ J. 2010;76(1):6-7.

41. Larouche R, Lloyd M, Knight E, et al. Relationship between active school transport and body mass index in grades 4-to-6 children. Pediatr Exerc Sci. 2011;23:322-30.

42. Longmuir PE, Boyer C, Lloyd M, et al. The Canadian assessment of physical literacy: methods for children in grades 4 to 6 (8 to 12 years). BMC Public Health. 2015;15:767-78.

43. Kitson A, Harvey G, McCormack B. Enabling the implementation of evidence based practice: a conceptual framework. Qual Health Care. 1998;7:149-58.

44. Hempenstall K. What does evidence-based practice in education mean? Aust J Learn Disabil. 2006;11(2):83-92.

45. Cook BG, Odom SL. Evidence-based practices and implementation science in special education. Counc Except Child. 2013;79(2):135-44.

46. Creswell JW. Research design: qualitative, quantitative and mixed methods approaches. 2nd ed. Thousand Oaks: SAGE; 2003.

47. Tremblay M, Lloyd M. Physical literacy: the missing piece. Phys Health Educ J. 2010;76(1):26-30.

48. Giblin S, Collins D, Button C. Physical literacy: importance, assessment and future directions. Sports Med. 2014;44:1177-84.

49. Sport Wales. Physical Literacy Programme for Schools (PLPS). 2014. Available from: http://sportwales.org.uk/communitysport/education/physical-literacy-programme-for-schools-(plps). aspx. Accessed 11 Feb 2016.

50. Song Y, Yang H, Lee E-Y, et al. Results from South Korea's 2016 report card on physical activity for children and youth. J Phys Act Health. 2016;13(11 Suppl. 2):274-8.

51. Tyler R, Mannello M, Mattingley R, et al. Results from Wales' 2016 report card on physical activity for children and youth: is Wales turning the tide on children's inactivity? J Phys Act Health. 2016;13(11 Suppl. 2):330-6.

52. United Nations Educational, Scientific and Cultural Organizations. Quality physical education: guidelines for policy-makers. Paris: UNESCO Publishing; 2015.

53. Dudley DA. A conceptual model of observed physical literacy. Phys Educ. 2015;72:236-60.

54. Ennis CD. Knowledge, transfer, and innovation in physical literacy curricula. J Sport Health Sci. 2015;4:119-24.

55. Lundvall S. Physical literacy in the field of physical education: a challenge and a possibility. J Sport Health Sci. 2015;4:113-8. 
56. Khan KS, Kunz R, Kleijnen J, et al. Systematic reviews to support evidence-based medicine: how to apply findings of healthcare research. London: Royal Society of Medical Press Ltd; 2003.

57. Higgins J, Green S. Cochrane handbook for systematic reviews of interventions, Version 5.1.0 [updated March 2011]. The Cochrane Collaboration, 2011. Available from: www.cochranehandbook.org. Accessed 6 Nov 2017.

58. Melendez-Torres G, Dickinson K, Fletcher A, et al. Systematic review and meta-analysis of effects of community-delivered positive youth development interventions on violence outcomes. J Epidemiol Commun Health. 2016. https://doi.org/10.1136/ jech-2015-206132.

59. Demetriou Y, Sudeck G, Thiel A, et al. The effects of schoolbased physical activity interventions on students' health-related fitness knowledge: a systematic review. Educ Res Rev. 2015;16:19-40.

60. Shamseer L, Moher D, Clarke M, et al. Preferred Reporting Items for Systematic Review and Meta-Analysis Protocols (PRISMA-P) 2015: elaboration and explanation. BMJ. 2015;2(350):g7647. https://doi.org/10.1136/bmj.g7647.

61. Evans D. Appraising systematic reviews. Chang Pract. 2000;(Suppl. 1):1-6.

62. Schlosser RW. Appraising the quality of systematic reviews. Focus. 2007;17:1-8.

63. Ahmed I, Sutton AJ, Riley RD. Assessment of publication bias, selection bias, and unavailable data in meta-analyses using individual participant data: a database survey. BMJ. 2012;3(344):d7762. https://doi.org/10.1136/bmj.d7762.

64. Higgins JPT, Altman DG. Assessing risk of bias in included studies. In: Higgins JPT, Green S, editors. Cochrane handbook for systematic reviews of interventions. Chichester: Wiley; 2008. p. 187-242.

65. Guest G, MacQueen K, Namey E. Applied thematic analysis. London: SAGE; 2012.

66. Braun V, Clarke V. Using thematic analysis in psychology. Qual Res Psychol. 2006. https://doi.org/10.1191/1478088706qp063oa.

67. Gibbs GR. Analyzing qualitative data. London: SAGE; 2007.

68. Guyatt GH, Oxman AD, Schünemann HJ, et al. GRADE guidelines: a new series of articles in the Journal of Clinical Epidemiology. J Clin Epidemiol. 2011;64:380-2.

69. Meader N, King K, Llewellyn A, et al. A checklist designed to aid consistency and reproducibility of GRADE assessments: development and pilot validation. Syst Rev. 2014;3:82.

70. Kentel J, Dobson T. Beyond myopic visions of education: revisiting movement literacy. Phys Educ Sport Pedagog. 2007; 12(2):145-62.

71. Chedzoy S, Burden R. Primary school children's reflections on physical education lessons: an attributional analysis and possible implications for teacher action. Think Skills Creat. 2009;4:185-93.

72. De Rossi P, Matthews N, MacLean M, et al. Building a repertoire: exploring the role of active play in improving physical literacy in children. Revista Universitaria De La Educación Física Y El Deporte. 2012;5:38-45.

73. Bannon C. An investigation into teaching strategies and assessment methods to foster physical literacy. ICSSPE Bull J Sport Sci Phys Educ. 2013;65:199-203.

74. Morgan K, Bryant A, Diffey F. The effects of a collaborative mastery intervention programme on physical literacy in primary PE. ICSSPE Bull J Sport Sci Phys Educ. 2013;65:140-53.

75. Vašíčková J, Hřibňák M. Physical literacy from the perspective of Czech pupils and teachers: results from a pilot study. ICSSPE Bull J Sport Sci Phys Educ. 2013;65:320-4.

76. Wainwright N. Physical literacy in the foundation phase in Wales. ICSSPE Bull J Sport Sci Phys Educ. 2013;65:130-9.
77. Millington B. Exergaming in retirement centres and the integration of media and physical literacies. J Aging Stud. 2015;35:160-8.

78. Barber W. Inclusive and accessible physical education: rethinking ability and disability in pre-service teacher education. Sport Educ Soc. 2016. https://doi.org/10.1080/13573322.2016. 1269004.

79. Francis C, Longmuir P, Boyer C, et al. The Canadian assessment of physical literacy: development of a model of children's capacity for a healthy, active lifestyle through a Delphi process. J Phys Act Health. 2016;13(2):214-22.

80. Lloyd R. Becoming physically literate for life: embracing the functions, forms, feelings and flows of alternative and mainstream physical activity. J Phys Act Health. 2016;35:107-16.

81. Sum R, Ha A, Cheng C, et al. Construction and validation of a perceived physical literacy instrument for physical education teachers. PLoS One. 2016;11(5):e0155610. https://doi.org/10. 1371/journal.pone.0155610.

82. Wainwright N, Goodway J, Whitehead M, et al. The foundation phase in Wales: a play-based curriculum that supports the development of physical literacy. Education 3-13. 2016;44(5):513-24.

83. Larsson H, Nyberg G. 'It doesn't matter how they move really, as long as they move.' Physical education teachers on developing their students' movement capabilities. Phys Educ Sport Pedagog. 2017;22(2):137-49.

84. Keske G, Gursel F, Ozlem A. Can you gain a healthy nutrition habit by physical literacy? Proc Soc Behav Sci. 2012;47:1097-102.

85. Bélanger M, Humbert L, Vatanparast $\mathrm{H}$, et al. A multilevel intervention to increase physical activity and improve healthy eating and physical literacy among young children (ages 3-5) attending early childcare centres: the Healthy Start-Départ Santé cluster randomised controlled trial study protocol. BMC Public Health. 2016;12(16):313. https://doi.org/10.1186/s12889-0162973-5.

86. Myers E. ICT and physical literacy: the use of podcasts as an educational tool to promote motivation and raise attainment in developing knowledge and understanding in physical education. ICSSPE Bull J Sport Sci Phys Educ. 2013;65:204-13.

87. Inchley J, Kirby J, Currie C. Longitudinal changes in physical self-perceptions and associations with physical activity during adolescence. Pediatr Exerc Sci. 2011;23(2):237-49.

88. Sharpe E, Forrester S, Mandigo J. Engaging community providers to create more active after-school environments: results from the Ontario $\mathrm{CATCH}$ kids club implementation project. J Phys Act Health. 2011;8(1):26-31.

89. McKee M, Breslin G, Haughey TJ, et al. Research into assessing physical literacy in Northern Ireland. ICSSPE Bull J Sport Sci Phys Educ. 2013;65:283-8.

90. Santos S, Jiménez S, Sampaio J, et al. Effects of the Skills4Genius sports-based training program in creative behavior. PLoS One. 2017;12(2):e0172520. https://doi.org/10.1371/ journal.pone.0172520.

91. Zuvela F, Bozanic A, Miletic D. POLYGON: a new fundamental movement skills test for 8 year old children: construction and validation. J Sports Sci Med. 2011;10(1):157-63.

92. Brunelle J-F, Blais-Coutu S, Gouadec K, et al. Influences of a yoga intervention on the postural skills of the Italian short track speed skating team. Open Access J Sports Med. 2015;6:23-35.

93. Kudláček M, Frömel K, Jakubec L, et al. Compensation for adolescents' school mental load by physical activity on weekend days. Int J Environ Res Public Health. 2016;13(3). https://doi. org/10.3390/ijerph13030308.

94. Myers E. Motivation and physical literacy: how can motivation levels of female pupils be improved within KS3 basketball 
physical education lessons? ICSSPE Bull J Sport Sci Phys Educ. 2013;65:182-8.

95. Allan V, Turnnidge J, Côté J. Evaluating approaches to physical literacy through the lens of positive youth development. Quest. 2017. https://doi.org/10.1080/00336297.2017.1320294.

96. Fink A. The role of the researcher in the qualitative research process. A potential barrier to archiving qualitative data. Qual Soc Res. 2000;1(3). http://www.qualitative-research.net/index. php/fqs/article/view/1021/2201.

97. Australian Sports Commission. Physical literacy: what does it mean for me? (1st ed.). Canberra (ACT): Australian Sports Commission; 2017. Available from: http://doi.org/10.4324/ 9780203881903 . Accessed 6 Nov 2017.

98. Whitehead M. Physical literacy: philosophical considerations in relation to developing a sense of self, universality and propositional knowledge. Sport Ethics Philos. 2007;1(3):281-99.

99. Pot N, Hilvoorde I. A critical consideration of the use of physical literacy in the Netherlands. ICSSPE Bull J Sport Sci Phys Educ. 2013;65:312-9.

100. Ames C. Classrooms: goals, structures, and student motivation. J Educ Psychol. 1992;84:261-71.

101. Heath C, Hindmarsh J, Luff P. Video in qualitative research: analysing social interaction in everyday life. London: SAGE; 2010.

102. Longmuir P. Understanding the physical literacy journey of children: the Canadian assessment of physical literacy. ICSSPE Bull J Sport Sci Phys Educ. 2013;65:276-82.

103. Department for Education and Skills. High quality PE and sport for young people. Nottinghamshire: DfES Publications; 2004.

104. Cross R. What time constraints face the junior school teaching taking on the role of student mentor? Mentor Tutor Partnersh Learn. 1999;7(1):5-21.
105. Dauncey M. National Assembly for Wales: research paper. Literacy and numeracy in Wales. Cardiff: National Assembly for Wales Commission; 2013.

106. Sprake A, Walker S. "Strike while the iron is hot": the duty of physical education to capitalise on its' compulsory position with a holistic curriculum underpinned by physical literacy. ICSSPE Bull J Sport Sci Phys Educ. 2013;65:42-50.

107. Penney D, Brooker R, Hay P, et al. Curriculum, pedagogy and assessment: three message systems of schooling and dimensions of quality physical education. Sport Educ Soc. 2009;14(4):421-42.

108. Bernstein B. Class codes and control, towards a theory of educational transmissions, vol. 3. London: Routledge and Keegan Paul; 1977.

109. Whitehead M, Almond L. Translating physical literacy into practice for all teachers. Phys Educ Matters. 2012;7:67-70.

110. Morgan K. Reconceptualizing motivational climate in physical education and sport coaching: an interdisciplinary perspective. Quest. 2017;67(1):95-112.

111. Epstein J. Family structures and student motivation: a developmental perspective. In: Ames C, Ames R, editors. Research on motivation in education, vol. 3. New York: Academic; 1989. p. $259-95$.

112. Fry M, Gano-Overway L. Exploring the contribution of the caring climate to the youth sport experience. J Appl Sport Psychol. 2010;22(3):294-304.

113. Appleton P, Nikos N, Quested E, et al. Initial validation of the coach-created Empowering and Disempowering Motivational Climate Questionnaire (EDMCQ-C). Psychol Sport Exerc. 2016;22:53-65.

114. Keegan R, Spray C, Harwood D, et al. The motivational atmosphere in youth sport: coach, parent, and peer influences on motivation in specializing sport participants. J Appl Sport Psychol. 2010;22(1):87-105. 